\title{
A DIVERSIDADE DAS PALAVRAS-CHAVE NOS TRABALHOS FINAIS DE GRADUAÇÃO DE PUBLICIDADE E PROPAGANDA DA UNIVERSIDADE FRANCISCANA ${ }^{1}$
}

\author{
THE DIVERSITY OF KEYWORDS IN THE ADVERTISING AND MARKETING'S \\ UNDERGRADUATE FINAL PROJECTS FROM THE FRANCISCAN UNIVERSTY
}

\author{
Daniela Venturini Mundstock ${ }^{2}$ e Taís Steffenello Ghisleni ${ }^{3}$
}

\section{RESUMO}

O presente artigo tem como objetivo analisar as palavras-chave usadas nos trabalhos finais de graduação pelos alunos do curso de Publicidade e Propaganda da Universidade Franciscana, desde a primeira turma (2006/2) até a última (2018/2). Para isso, foi então feito um levantamento exploratório e descritivo de todas as palavras-chave utilizadas durante as 24 turmas que passaram pela instituição. Com isso, foi identificado que a escolha dessas palavras-chave é muito ampla e diversa, tendo muitas palavras que não se repetem nenhuma das vezes. A diversidade foi relevante, uma vez que as palavras repetidas foram poucas e prevaleceu uma contraposição de temas.

Palavras-chave: Comunicação; Publicidade e Propaganda; Palavras-chave.

\section{ABSTRACT}

This article aims to analyze the keywords used in final undergraduate projects by Advertising and Marketing students from the Franciscan University, from the first class (2006/2) to the last one (2018/2). To do so, it was made an exploratory and descriptive survey of all the keywords that were used during the 24 classes that graduated. Thereby, it was identified that the choice of these keywords is very wide and diverse, and many words were not repeated at all. Diversity was relevant because the repeated keywords were few and a contrast of themes prevailed.

Keywords: Communication; Advertising and Marketing; Keywords.

\footnotetext{
${ }^{1}$ Trabalho de Iniciação Científica.

${ }^{2}$ Acadêmica do Curso de Publicidade e Propaganda da Universidade Franciscana - UFN. E-mail: danimundstock@gmail.com ${ }^{3}$ Doutora. Professora do Curso de Publicidade e Propaganda e do Mestrado em Humanidades e Linguagens da Universidade Franciscana - UFN. E-mail: taisghisleni@yahoo.com.br
} 


\section{INTRODUÇÃO}

Este projeto nasceu com o objetivo de dar continuidade à uma pesquisa realizada em 2012 no curso de Publicidade e Propaganda da Universidade Franciscana, pela então acadêmica Elisiane Rosa Carneiro, com orientação da Professora Taís Steffenello Ghisleni. O trabalho, que foi intitulado "Potencialidades e Tendências no Curso de Publicidade e Propaganda da Unifra", surgiu a partir percepção do crescente interesse na busca dos alunos por novas temáticas de estudo, sentindo assim uma necessidade de identificação de novas linhas de pesquisa para o curso.

As palavras-chave são uma forma de garantir sucesso na pesquisa de determinado tema, uma vez que elas auxiliam e refinam as buscas de acordo com o interesse do pesquisador. O objetivo da palavra-chave é representar o texto de forma mais prática, de modo que possa sintetizar o conteúdo temático. Por isso, as palavras-chave têm de ser termos de conhecimento da área a qual o autor fala.

\footnotetext{
Portanto, para determinação de palavras-chaves o autor deverá ter uma visão sobre o texto e a organização do seu conteúdo de modo a representá-lo conforme seu assunto principal e, em outro plano, o objetivo de representação do conteúdo documentário, a visão sobre a demanda do leitor previsto (FUJITA, 2004, p. 258b).
}

Já as linhas de pesquisas são definidas pelo crescente interesse em novas áreas de estudo, uma vez que os estudantes buscam ir além do que já fora pesquisado antes, introduzindo cada vez mais tópicos e assuntos diferentes. Segundo Jacks (2008), as tendências de pesquisa da época eram definidas como "globalização, novas tecnologias, e-commerce, empresas ponto.com, nova economia, virtualidade" (apud Carneiro, 2012). Agora pode-se dizer que esses temas não estão mais tanto em uso, já que novas linhas de pensamento foram inseridas e geraram interesse em uma escala muito maior.

A transformação tão instantânea da publicidade faz com que os estudantes estejam sempre atentos nas novas tendências. O que é um conteúdo relevante agora, amanhã pode não ser mais. A verdade é que, com tantos conteúdos disponíveis nas mídias, os assuntos tornam-se efêmeros e, consequentemente, substituíveis. A mídia passou por grandes evoluções e diferentes momentos até chegar ao cenário atual.

Santaella (2007) relata que as pessoas "constituem-se como massa não por estarem ligados pela presença em um mesmo local físico, mas por adquirirem experiências similares através dos meios de comunicação, sem que compartilhem contextos similares de vida". A publicidade, então, precisa girar em torno do conteúdo que o espectador deseja, o que é esperado seja pela mídia televisiva, internet, rádio ou qualquer outro meio.

Dependendo da mídia em que o gênero publicitário é veiculado, ele necessariamente tem de se amoldar às exigências e possibilidades abertas pela mídia em questão. Quando se trata das enumeráveis plataformas, ou melhor, distintas ecologias do "planeta internet", as condições que se apresentam para a mensagem publicitária se multiplicam (SANTAELLA, 2017, p. 151). 
De acordo com uma pesquisa realizada pelo Conselho Executivo de Normas-Padrão CENP e divulgada no site Meio Mensagem, em abril de 2019, a compra de mídia do ano de 2018 foi praticamente igual a de 2017, na qual continua a predominar a TV aberta como a mídia com o maior investimento e maior poder de atração das verbas dos anunciantes, com um total de 58,3\% dos investimentos. Em segundo lugar está a internet, com 17,7\%, uma grande diferença ainda em relação à televisão.

E não é somente a publicidade que está em constante mudança: o telespectador também. Justamente por isso é importante que as marcas saibam entender por que transformações o seu público está passando. Ghisleni (2016, p. 52) cita que "com o passar do tempo os hábitos e comportamentos dos indivíduos são modificados, e com a publicidade ocorre o mesmo". A partir disso, é importante ressaltar como a publicidade está em constante mudança o tempo todo, e precisa buscar novas formas para atrair o público a partir do entendimento sobre o que cada espectador deseja.

A partir do contexto exposto, o presente artigo tem como objetivo analisar as palavras-chave usadas nos trabalhos finais de graduação pelos alunos do curso de Publicidade e Propaganda da Universidade Franciscana, nas suas 24 primeiras turmas formadas, e isso inclui trabalhos de 2006 até 2018. De posse das informações sobre as palavras-chave utilizadas pelos alunos em suas monografias na pesquisa anterior e na pesquisa atual será possível analisar se houve ou não uma mudança nas temáticas que são estudadas no curso de Publicidade e Propaganda da Universidade Franciscana.

\section{PALAVRAS-CHAVE}

As palavras-chave são o principal instrumento de buscas de um texto. Isso porque elas facilitam as buscas, refinando mais ainda os resultados e trazendo precisão no assunto que o pesquisador está procurando. Este procedimento, no âmbito dos artigos científicos, pode-se revelar útil para a indexação em mecanismos de pesquisa ou categorização do texto (ERCAN; CICEKLI, 2007). A organização da informação e a sua representação são aspetos essenciais da ciência da informação, que tem como uma das suas finalidades a partilha da informação, enquanto recurso estratégico na cadeia que gera o conhecimento (TONELLO; LUNARDELLI; ALMEIDA JÚNIOR, 2012).

Segundo definições da NBR 6028 da Associação Brasileira de Normas Técnicas (ABNT, 2003), palavra-chave é a palavra representativa do conteúdo do documento, escolhida, preferentemente, em vocabulário controlado. As palavras-chave devem figurar logo abaixo do resumo, antecedidas da expressão "Palavras-chave", separadas entre si por ponto e finalizadas também por ponto. O termo palavra-chave não precisa, necessariamente, ser composto de uma só palavra. Pelo contrário, quanto mais palavras-chaves forem definidas, mais refinadas serão as buscas relacionadas aos mesmos assuntos. 


\section{PUBLICIDADE E PROPAGANDA}

Partindo do conceito definido pelas "Normas-padrão da atividade publicitária”, elaboradas a partir da lei n. 4.680/65 e dos decretos n. 57.690/66 e n. 2.262/97, no item 1.1. do capítulo 1 (conceitos básicos), a "Publicidade ou propaganda: é nos termos do art. $2^{\circ}$ do dec. n. 57.690/66 qualquer forma remunerada de difusão de ideias, mercadorias, produtos ou serviços por parte de um anunciante identificado" (CENP, 1998). Assim, a publicidade e a propaganda utilizam de novas formas para vender um anúncio, a fim de chamar atenção do público a partir de meios criativos e atrativos.

Embora pareçam sinônimos, os conceitos de publicidade e de propaganda são diferentes. Segundo Vasconcelos (2018, online), “propaganda é a atividade associada à divulgação de ideias (políticas, religiosas, partidárias etc.) para influenciar um comportamento”, ou seja, nada mais é do que um conjunto de ideias com o objetivo de dar conhecimento a algo ou alguém. Quanto à publicidade, o autor conceitua como:

Já publicidade, em sua essência, quer dizer tornar algo público. Com a revolução industrial,
no fim do século 19, e o fortalecimento do capitalismo, a publicidade ganhou um sentido
mais comercial, e passou a ser uma ferramenta de comunicação para convencer o público a
consumir um produto, serviço ou marca. (VASCONCELOS, 2018, online).

Segundo Ghisleni (2016, p. 53), "para atingir o consumidor, a publicidade precisa estar aberta para mudanças nas suas práticas, tornando-a mais profunda, assertiva e consciente que as pessoas e as marcas estão constantemente mudando, buscando novas experiências e sensações”. Para que isso aconteça, então, o publicitário precisa entender e conhecer os desejos do seu público-alvo, a fim de atraí-lo para o ato da compra.

\section{PUBLICIDADE: DO TRADICIONAL AO DIGITAL}

De acordo com Gonçalez (2009), a publicidade nasceu quando alguém disse a alguém que tinha alguma coisa a oferecer. De fato, nunca se soube o momento exato em que a publicidade surgiu: ela sempre esteve ali. Há vários momentos em que foi usada esta técnica de comunicação para vender e criar hábitos de consumo. O autor também cita que:

\footnotetext{
A propaganda que conhecemos, começou a tomar forma com a igreja católica, com a criação de uma congregação religiosa para propagar a fé no mundo. [...] Já a publicidade toma a forma que conhecemos no final do século XIX com a Revolução Industrial. [...] Assim como na propaganda, o surgimento dos meios de comunicação, e seu desenvolvimento técnico, contribuíram para o avanço da publicidade (GONÇALEZ, 2009, p. 9).
}

Ao longo dos anos, surgiram diversas formas de fazer publicidade: jornais, rádio, televisão, agências de publicidade, outdoors e várias outras opções para aqueles que queriam vender algum 
produto ou serviço. Com isso, os vendedores também se utilizaram da internet para atrair um outro olhar, buscando cada vez mais tecnologia e inovação para as suas empresas. Ghisleni (2016, p. 52) cita que "desde o surgimento da internet e a criação de ações de marketing voltadas para a rede mundial, a publicidade também renovou em seus meios de expressão e comunicação". Com tantas

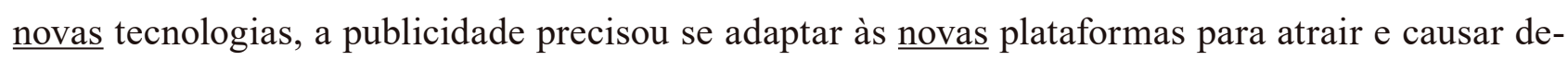
sejo aos consumidores.

Após a onda dos computadores, surgiu uma nova tecnologia que, literalmente, cabia no bolso de todos os usuários: os smartphones. Com o surgimento dos celulares inteligentes, a publicidade teve de se adaptar e incluir uma nova linguagem para atrair atenção do público. Todos os dias os anúncios invadem as telas dos celulares sem mesmo um aviso prévio, forçando o usuário a assistir determinada publicidade antes de poder continuar navegando na sua rede social. Ainda segundo Ghisleni (2016, p. 68), “o panorama da publicidade mudou muito nos últimos anos, e no setor online é que estas mudanças são mais visíveis, já que a publicidade precisou se adaptar aos novos tempos, em que a mobilidade e a comunicação integrada estão em foco". Hoje em dia, com a praticidade do celular, a compra por um clique tornou-se tão normal quanto ir ao mercado. Com isso, as empresas tiveram que buscar novas formas de comunicação, a fim de se engajarem nas redes sociais com uma linguagem mais amigável, mostrando que se importam com seus consumidores.

\section{METODOLOGIA}

A metodologia utilizada para a construção desta pesquisa é exploratória e descritiva. Inicialmente foi feito um levantamento das palavras-chave utilizadas nos trabalhos finais de graduação de todos os alunos das 24 turmas que passaram pela instituição. Os dados que relatavam as palavras-chave utilizadas pelas 11 primeiras turmas foram coletados de uma pesquisa já realizada por Carneiro e Ghisleni (2012), e a esses dados somamos a coleta das próximas 13 turmas do curso.

Reforçamos que a coleta de dados foi contemplada de forma quantitativa e apreciou todas as palavras-chave utilizadas nos Trabalhos Finais de Graduação das 24 turmas que se formaram desde o início do curso, em 2003 até 2018. O período da coleta incluiu desde 2006, quando a primeira turma defendeu seus trabalhos finais, até o segundo semestre de 2018. De posse dos dados a respeito de todas palavras utilizadas foi realizado um cruzamento de dados e a escrita dos resultados coletados.

\section{RESULTADOS E DISCUSSÃO}

O levantamento de todas as palavras-chave utilizadas nos Trabalhos Finais de Graduação, do curso de Publicidade e Propaganda, da Universidade Franciscana (UFN) permitiu observar as diferentes temáticas estudadas pelos alunos e a evolução destas temáticas ao longo do curso. Nesta 
análise, identificou-se que muitas palavras foram usadas, deixando evidente a diversidade das temáticas estudadas.

Uma pesquisa anterior, intitulada "Potencialidades e tendências no curso de publicidade e propaganda da Unifra" e realizada pela então acadêmica Elisiane Rosa Carneiro, com orientação da Professora Taís Steffenello Ghisleni, que analisou 11 turmas do curso de Publicidade e Propaganda, durante os 6 primeiros anos de curso, período de 2006 a 2012/1, resultou em 516 palavras-chave diferentes, sendo que dessas, 428 não se repetiram nenhuma vez. Com isso, foi possível perceber a grande dispersão de assuntos e palavras que são pesquisados, embora, naquele momento a palavra-chave mais utilizada foi "Publicidade", repetindo-se 48 vezes, seguindo das palavras "Marketing", num total de 23 vezes, "Marca" (20x), Internet (18x), Consumo (17x), e outras mais.

O gráfico 01 mostra que, de um total de 516 palavras utilizadas, apenas 98 , ou seja 19\% eram recorrentes e se repetiam nos trabalhos. A maior soma, ou seja, $81 \%$ representavam palavras que se não se repetiam em outras pesquisas.

Gráfico 1 - Palavras-chave utilizadas nas 11 primeiras turmas.

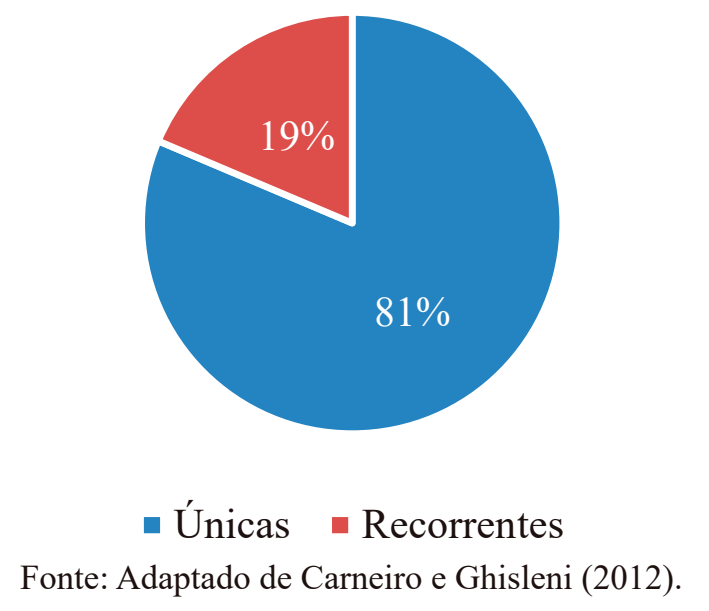

Essa pesquisa agregou aos dados anteriores a análise das próximas 13 turmas, contabilizando os dados dos anos de 2012/2 a 2018/2, e neste período utilizaram-se, ao todo, 499 palavras, sendo que 384 palavras não foram repetidas nenhuma vez. As palavras que mais se repetiram, em ordem decrescente, foram: Publicidade (58x), Comunicação (45x), Marca (24x), Publicidade e Propaganda (14x), Cinema (11x), Propaganda (11x), Audiovisual (10x), Cultura (10x), Facebook (10x), Marketing Digital (10x), Consumo (9x), Estética (9x), Marketing (8x), Mídias sociais (8x), e outras 101 outras palavras diferentes que, somando as vezes que foram utilizadas, repetiram-se 314 vezes.

O gráfico 02 mostra que, de um total de 499 palavras utilizadas, apenas 115, ou seja $20 \%$ eram recorrentes e se repetiam nos trabalhos. A maior soma, ou seja, 80\% representavam palavras que se não se repetiam em outras pesquisas.

Um dado que foi possível perceber nesta pesquisa é que falta padronização no uso das palavras-chave já que, por exemplo: Publicidade foi utilizada 58 vezes, Publicidade e Propaganda foi 
utilizada 14 vezes e a palavra Propaganda foi utilizada 11 vezes. Se existisse uma padronização proposta pelo curso, todas essas versões poderiam refletir uma palavra única, e que represente o curso de maneira ampla.

Gráfico 2 - Palavras-chave utilizadas nas 13 últimas turmas.

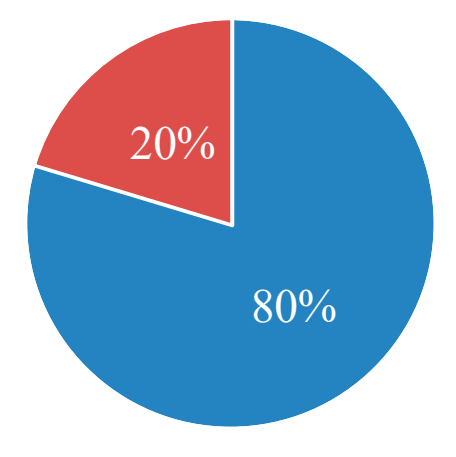

\section{Únicas Recorrentes}

Fonte: Construção do Autor

A partir o quadro comparativo, é possível perceber que a palavra ainda mais utilizada é "Publicidade", ficando em primeiro lugar em ambas as pesquisas. Nessa última pesquisa é notável que as 4 primeiras palavras mais utilizadas são mais padronizadas em relação ao curso, sendo elas Publicidade, Comunicação, Marca, e Publicidade e Propaganda. Também se percebe a ausência de repetição de algumas palavras-chave que apareceram na primeira pesquisa, como "Agências de Publicidade e Propaganda", e a inclusão de outras como "Facebook", "Audiovisual”, "Marketing Digital” e "Mídias sociais“, mostrando como os interesses e a tecnologia mudou nos últimos anos.

Quadro 1 - Comparação entre as duas pesquisas sobre palavras-chave.

\begin{tabular}{|c|c|}
\hline $\begin{array}{c}\text { TURMAS } 2006-2012 / 1 \\
(11 \text { TURMAS) }\end{array}$ & $\begin{array}{c}\text { TURMAS } 2012 / 2-2018 / 2 \\
\text { (13 TURMAS) }\end{array}$ \\
\hline Publicidade $(48 \mathrm{x})$ & Publicidade (58x) \\
\hline Marketing $(23 \mathrm{x})$ & Comunicação $(45 \mathrm{x})$ \\
\hline Marca $(20 x)$ & Marca $(24 x)$ \\
\hline Internet $(18 \mathrm{x})$ & Publicidade e Propaganda (14x) \\
\hline Consumo $(17 \mathrm{x})$ & Cinema $(11 \mathrm{x})$ \\
\hline Comunicação (15x) & Propaganda (11x) \\
\hline Comportamento do Consumidor $(15 \mathrm{x})$ & Audiovisual (10x) \\
\hline Moda (14x) & Cultura $(10 \mathrm{x})$ \\
\hline Estratégias (12x) & Facebook (10x) \\
\hline Mídia $(11 \mathrm{x})$ & Marketing Digital (10x) \\
\hline Identidade $(10 \mathrm{x})$ & Consumo $(9 \mathrm{x})$ \\
\hline Propaganda $(8 \mathrm{x})$ & Estética $(9 \mathrm{x})$ \\
\hline Agências de Publicidade e Propaganda (8x) & Marketing (8x) \\
\hline Cinema $(8 x)$ & Mídias sociais $(8 \mathrm{x})$ \\
\hline Consumidor $(7 \mathrm{x})$ & Moda $(8 x)$ \\
\hline
\end{tabular}

Fonte: Construção do Autor. 
Os dados mostram que apesar de uma leve melhora na ampliação das recorrências, ainda é muito maior a utilização de palavras-chave que são utilizadas uma única vez, e isso, apesar de evidenciar a diversidade das temáticas estudadas no curso, não fortalece as linhas de pesquisa e o contexto do curso de forma geral.

\section{CONSIDERAÇÕES FINAIS}

A partir das análises dos resultados, ficou claro como a área de Publicidade e Propaganda, mais especificamente o curso de graduação da Universidade Franciscana, abrange vários temas que podem ser estudados mais a fundo. Pode-se observar também que, com a grande diversidade de palavras-chave escolhida pelos alunos, ainda assim algumas palavras em comum prevalecem, aparecendo repetidamente em muitos dos estudos. A palavra-chave Publicidade é a que mais aparece dentre as demais, construindo assim, um alinhamento do curso em relação à palavra-chave que mais o representa.

Apesar disso, ainda prevalecem as palavras que não se repetem nenhuma vez, sendo essas mais da metade dentre todas as palavras-chave pesquisadas em todos os trabalhos analisados. Com isso, é notável que as pesquisas realizadas no curso ainda não têm um foco específico, uma vez que sua diversidade é exageradamente maior. Porém, mesmo com toda essa contraposição, os alunos ainda assim optam, muitas vezes, por utilizar palavras-chave mais comuns como "publicidade" e "comunicação".

A coleta realizada no primeiro trabalho, com as 11 primeiras turmas do curso e a coleta realizada nesse trabalho mostrou que não houve grande diferença entre as duas pesquisas, uma vez que dos resultados obtidos nas primeiras 11 turmas, 19\% das palavras-chave são recorrentes, e $81 \%$ são únicas. Já na segunda pesquisa, mesmo com a diferença de 2 turmas a mais, os resultados foram praticamente iguais, com $20 \%$ de palavras recorrentes e $80 \%$ de palavras únicas.

É importante lembrar que as palavras-chave variam de acordo com o contexto de cada pesquisa, por isso é comum que se tenha uma diversidade de palavras dentro de um curso, principalmente na área da Publicidade e Propaganda, já que é um curso de comunicação que abrange muitas áreas diferentes. Agora, com a ambiência digital, é possível que sejam inseridas ainda mais palavras relacionadas à essa temática.

A partir do resultado desta pesquisa, aliada às temáticas presentes na nova matriz curricular que iniciou em 2019, o Laboratório de Pesquisa em Comunicação se propõe a organizar uma lista de palavras-chave recorrentes que representem o curso e divulgar aos alunos e professores a partir do próximo semestre, para que usem, preferencialmente as palavras com a grafia recomendada a fim de otimizar as recorrências e o fortalecimento das temáticas estudadas no Curso. 


\section{REFERÊNCIAS}

ABNT NBR 6028, Informação e documentação - Resumo - Apresentação. Disponível em: https:// bit.ly/2XX2g0j. Acesso em: 03 abr. 2019

AQUINO, Italo Souza; AQUINO, Itiel Souza. Análise sobre a forma da escrita de palavras-chave em artigos científicos na área de ciências agrárias publicados no período de 1999 a 2011. Encontros Bibli: revista eletrônica de biblioteconomia e ciência da informação, v. 18, n. 37, p. 227-238, mai./ago., 2013. Disponível em: https://bit.ly/2MUxyP6. Acesso em: 03 abr. 2019

CENP - Conselho Executivo das Normas-Padrão. Do relacionamento comercial entre anunciantes, agências de publicidade e veículos de comunicação, frente à lei nº 4.680/65. 1998.

CARNEIRO, Elisiane Rosa; GHISLENI, Taís Steffenello. Potencialidades e tendências no curso de publicidade e propaganda da unifra. Disciplinarum Scientia. Série: Ciências Sociais Aplicadas, Santa Maria, v. 8, n. 1, p. 19-29, 2012.

ERCAN, G.; CICEKLI, I. Using lexical chains for keyword extraction. Information processing and management, v. 43, p. 1705-1714, 2007. Disponível em: https://bit.ly/2B0sdTy. Acesso em: 03 abr. 2019

FUJITA, M. S. L. A Representação documentária de artigos científicos em educação especial: orientação aos autores para determinação de palavras-chaves. Rev. Bras. Ed., Marília, v. 10, n. 1, p. 257-272, set./dez. 2004

GHISLENI, Taís Steffenello. Portais institucionais na web: análise de anúncios publicitários no ecossistema midiático. 25/11/2016. 297p. Tese (Doutorado). Universidade Federal de Santa Maria. Santa Maria, Centro de Ciências Sociais e Humanas, Programa de Pós-Graduação em Comunicação. 2016.

GONÇALEZ, Márcio Carbaca. Publicidade e Propaganda. Curitiba: IESDE Brasil S.A., 2009.

GONÇALVES, Aline Lima; Uso de resumos e palavras-chave em Ciências Sociais: uma avaliação. Encontros Bibli: revista eletrônica de biblioteconomia e ciência da informação, v. 13, núm. 26, 2008, Universidade Federal de Santa Catarina Florianópolis, Brasil. Disponível em: https://bit.ly/3hoVE2g. Acesso em: 03 abr. 2019 
MEIO E MENSAGEM: Cenp-Meios: compra de mídia em 2018 foi praticamente igual à de 2017. Disponível em: https://bit.ly/2MYxm0Z. Acesso em: 24 abr. 2019.

MORAES, Maria Helena Machado de; MIRANDA, Angélica Conceição Dias. Mestrado Profissional no Ensino de Ciências e suas similaridades na produção do conhecimento: estudos das palavras-chave das dissertações defendidas conforme Avaliação Trienal 2010-2012. Revista Thema, [S.1.], v. 14, n. 3, p. 167-181, ago. 2017. Disponível em: https://bit.ly/3fpjn0J. Acesso em: 03 abr. 2019.

SANTAELLA, Lucia. Redação publicitária digital. Curitiba: InterSaberes, 2017.

SANTAELLA, Lucia. Linguagens líquidas na era da mobilidade. São Paulo: Paulus, 2007.

TONELLO, I.; LUNARDELLI, R.; ALMEIDA JUNIOR, O. Palavras-chave: possibilidades de mediação da informação. Ponto de Acesso, v. 6, p. 21-34, 2012. Disponível em: https://bit.ly/3cVVzQq. Acesso em: 03 abr. 2019.

VASCONCELOS, Yuri. Qual a diferença entre publicidade e propaganda? Mundo Estranho, Grupo Abril, 2018. Disponível em: https://bit.ly/2UHtlTc. Acesso em: 10 jul. 2019. 